\title{
Gabriele A. Krombach, Andreas H. Mahnken: Body imaging: thorax and abdomen anatomical landmarks, image findings, diagnosis
}

\author{
Thieme, Stuttgart New York Delhi Rio de Janeiro, 2018, 497 p., format $30 \times 22.5 \times 4 \mathrm{~cm}, 1509$ \\ illustrations ISBN 978-3-13-205411-0, eISBN 978-3-13-205421-9\$4
}

\section{Bruno Grignon ${ }^{1}$}

Received: 30 November 2018 / Accepted: 5 December 2018 / Published online: 7 December 2018

○) Springer-Verlag France SAS, part of Springer Nature 2018

In keeping with its title, this book aims at providing the most important anatomic landmarks of all the modalities of imaging of the chest and the abdomen, to provide a step-bystep guide to interpret imaging findings, and make a diagnosis. Online access to additional media and an e-book is also provided.

It is composed of two main parts, respectively, devoted to the chest and the abdomen. Part 1 is divided into four sections: the mediastinum, the heart and pericardium, the large vessels, and the lung and pleura. The chapters of Part 2 subsequently deal with the liver, the gallbladder, the pancreas, the gastrointestinal tract, the spleen and lymphatic system, the adrenal glands, the kidney and urinary tract, the female pelvis, and finally the male pelvis.

Based on the triad of clinical symptoms, anatomical landmarks, and radiological findings, each section is composed of concise chapters very clearly presented, richly illustrated, and containing tables and color boxes highlighting important short messages. The text is systematically arranged by subheads (brief definition, clinical features, imaging signs differential diagnosis, and key points), allowing the reader to quickly locate specific areas of interest. The topics covered encompass the breadth of the field in routine clinical use. Main bibliography references are presented at the end of each chapter.
More than 1500 illustrations are provided. The book focuses on the sectional modalities of computed tomography and magnetic resonance imaging, but includes plain radiograph and ultrasound images. In addition, numerous explanatory drawings of anatomy, embryology, and pathology are displayed.

This book is the English translation of the first German edition published in 2005. The two editors are Gabriele A. Krombach, Professor, Department of Diagnostic and Interventional Radiology, Giessen University Hospital, Giessen, Germany, and Andreas H. Mahnken, Professor, Department of Diagnostic and Interventional Radiology, Marburg University Hospital, Marburg, Germany. A panel of 13 German contributors has collaborated in writing this book.

Easy-to-use, concise, and richly illustrated, this book is chiefly designed to radiology residents, and may also be an interesting tool for seasoned physicians.

Author contributions BG: manuscript writing and editing.

\section{Compliance with ethical standards}

Conflict of interest The author declares that he has no conflict of interest.
Bruno Grignon

b.grignon@chu-nancy.fr

1 University of Lorraine, CHU Nancy, Nancy, France 